\title{
Vertical Handover Algorithm for Telemedicine Application in 5G Heterogeneous Wireless Networks
}

\author{
Boh Wen Diong, Mark Irwin Goh, Seng Kheau Chung, Ali Chekima, Hoe Tung Yew* \\ Faculty of Engineering, Universiti Malaysia Sabah \\ Kota Kinabalu, Malaysia
}

\begin{abstract}
In this fast-paced technology era, the advancement of telecommunication systems has made many advanced technologies possible. With the help of the 5G technology, more technologies will become a reality and telemedicine is one of them. Numerous studies have shown that the fatal rate of ischemic heart disease cases can be reduced by sending the realtime patient health data from an ambulance to the medical centre so that healthcare professionals can make early preparation and give immediate treatment in the golden hour. 5G technology offers a high data rate and low latency. However, the coverage of 5G is small compared to $4 \mathrm{G}$. It will induce a high number of unnecessary handovers when an ambulance traverses the 5G networks at high speed and lead to degradation of services quality. Therefore, a fast and accurate vertical handover decision-making algorithm is needed to minimize unnecessary handover in high-speed scenarios. This paper proposes a handover algorithm that integrates the Travelling Time Estimation, Fuzzy Analytic Hierarchy Process (FAHP) and Technique for order of preference by similarity to ideal solution (TOPSIS) algorithms to reduce unnecessary handover in 5G heterogeneous networks. The simulation results show that the proposed algorithm has successfully reduced up to $80.3 \%$ of handovers compared to FAHP-TOPSIS based handover algorithm in the high-speed scenario. The proposed handover algorithm can improve the quality of telemedicine services in high-speed scenarios.
\end{abstract}

Keywords-Mobile terminal; vertical handover; heterogeneous networks; unnecessary handover; telemedicine; TOPSIS

\section{INTRODUCTION}

In this fast-paced technology era, the advancement of telecommunication systems has made many advanced technologies possible. With the help of the Fifth Generation (5G) telecommunication technology, more technologies will become a reality and telemedicine is one of them. The quality of telemedicine services is greatly affected by network quality. The higher the bandwidth, the better the quality of service. However, the bandwidth requirement is depending on the types of telemedicine service. For example, the transmission of medical video or images requires higher bandwidth than vital signs.

Apart from the network quality, the network coverage issue needs to be taken into consideration. A telemedicine system that relies on a single network cannot guarantee that the user always connects to the healthcare centre. A telemedicine system that can connect to heterogeneous wireless networks is

*Corresponding Author

This research was supported by the Ministry of Higher Education (KPT) Malaysia, Fundamental Research Grant Scheme FRGS/1/2020/TK0/UMS/02/2 (UMS ID FRG0535-2020). required to allow the users to connect to the network anywhere [1].

Studies have proved that the fatality rate of ischemic heart disease cases is noticeably reduced with the help of telemedicine [2]. One of the methods could be to send realtime patient health data from an ambulance to the medical centre so that healthcare professionals can prepare early, such as setting up the operating theatre and give immediate treatment once the patient arrived at emergency centre. This method is possible with the help of $5 \mathrm{G}$ network because it offers a high data rate and low latency [3][4]. But the 5G network coverage is small compared to $4 \mathrm{G}$. It will induce a high number of handovers when the ambulance traverses $5 \mathrm{G}$ networks at high speed. A high number of handovers or unnecessary handovers will cause packet loss and data corruption, leading to degradation in telemedicine services.

The integrity of real-time health data transmitted from a high-speed ambulance to the medical centre is crucial to prevent misinterpretation and misdiagnosis by healthcare professionals. Therefore, an effective and precise handover decision making algorithm for telemedicine application in $5 \mathrm{G}$ heterogeneous networks is proposed to minimize the unnecessary handover when the ambulance is traversing $5 \mathrm{G}$ heterogeneous wireless networks at high speed. The proposed algorithm should also select the network that fulfils the service requirements while maintaining user satisfaction at the highest level.

The rest of the paper is organized as follow. Section II reviews the existing handover algorithms in heterogeneous networks. Sections III and IV discuss the methodology of the proposed handover algorithm and experiment setup, respectively. The performance of the proposed handover algorithm is discussed in Section V. Section VI concludes the paper.

\section{RELATED WORK}

Vertical handover allows a mobile terminal (MT) to switch from one network to another without losing the connection. It consists of three phases which are handover initiation, decision, and execution [5]. The handover initiation utilizes the Media Independent Handover Function to discover and retrieve available network information [6]. The handover decision selects the most suitable network based on the network information. The executive phase establishes the connection with the targeted network and releases the serving network [7]. 
A handover decision scheme proposed by [8] employed the change rate of the Received Signal Strength (RSS) to predict the travelling distance in a wireless local area network (WLAN) coverage area. MT triggers handover to the network candidates that estimated travelling time is greater than the predefined time threshold. The algorithm has successfully reduced the unnecessary handover rate. However, the handover delay is high because two RSS points within WLAN coverage are needed for the travelling time estimation process. Author in [9] proposed a handover algorithm that combines the travelling distance prediction technique with the bandwidth based handover algorithm. The bandwidth based handover algorithm is less complicated compared to the multi-criteria and intelligence-based handover schemes. It simplifies the handover process and reduces the handover delay. The advantage of applying the travelling time estimation technique is that it reduces the probability of unnecessary handovers when MT traverses the small cell networks at high speed.

An adaptive network selection mechanism for telemedicine systems is proposed by [10]. This algorithm finds the best wireless network based on the user's health condition and service requirements. Similarly, authors in [11] presented a user-centric based handover algorithm for telecardiology applications. This algorithm considers the type of telecardiology services, contextual data such as MT velocity and patient health conditions. User satisfaction has greatly improved by reducing handover failures and selecting the lowcost network while maintaining the service quality. However, this work excluded the small cell network from high-speed environment.

Authors in [11,12] proposed multi-attribute decision making (MADM) based handover algorithms. These schemes show the best use of the channel to efficiently transmit the biosignal by offloading the procedure between $\mathrm{Wi}-\mathrm{Fi}$ and Long-Term Evolution (LTE). The RSS and signal-to-noise ratio (SNR) values were measured and used to compare with their threshold values. The algorithms reduced the unnecessary handover and provided constant data transmission. The telemedicine-based handover decision making (THODM) algorithm presented by [14] selects the best network based on the MT velocity, user setting, and predefined database. This algorithm has successfully reduced the unnecessary handover rate and optimized the usage of small cell networks in a highspeed environment. However, it did not take QoS parameters into consideration.

Author in [1] presented an Improved-TOPSIS based algorithm for telemedicine application. TOPSIS approach is used because of its multi-attribute decision analysis method, which simultaneously estimates both the best and worst alternatives. The proposed algorithm maximized user satisfaction by selecting the network based on user preference. An intelligent based MADM handover algorithm has been used to improve the handover performance. Authors in [15] proposed MADM handover algorithm that integrated FAHP with TOPSIS and VIKOR algorithm. FAHP was used to determine the weights of each criterion, while FAHP and VIKOR were used to find the best network to initiate handover. The limitation of the FAHP-TOPSIS algorithm is that it will induce a high number of unnecessary handovers at the high- speed scenario. Furthermore, authors in [16] presented a neural network based MADM handover algorithm. Authors in [17] presented a Genetic algorithm (GA) based MADM handover algorithm. Authors in [18] proposed an algorithm using FAHP weighting based on user preference and the TOPSIS method to rank the network candidates. The algorithm is able to lower the total number of handovers and maintain the service quality. However, the authors only considered MT moving at low speed. The number of handovers and unnecessary handovers might increase when MT moves at high speed.

The intelligence based MADM based handover decision making system is suitable for telemedicine application because it can accurately select the best network. Moreover, the more handover criteria taken into account, the better the handover performance. However, most existing MADM based handover algorithms did not consider handover performance at highspeed scenarios. In this paper, we proposed a new handover decision making algorithm that integrates the travelling time estimation technique with the intelligence based MADM handover algorithm.

\section{MethodolOGY}

The proposed handover scheme integrates the Travelling Time Estimation, FAHP and TOPSIS algorithms. The Travelling Time Estimation algorithm is used to predict the travelling time in the small cell networks. FAHP algorithm is selected to determine the handover criteria weights that will be used in the TOPSIS algorithm. TOPSIS ranks all the network candidates and selects the best network to initiate handover.

\section{A. Travelling Time Estimation}

The Travelling Time Estimation algorithm prevents unnecessary handover to small cell networks by excluding the network candidates that have an estimated travelling or network connection time less than the predefined threshold time. This algorithm only applies in small cell networks such as WLAN and 5G. The threshold time is set at two seconds $[13,19]$. The scenario of MT traversing the small cell network is illustrated in Fig. 1. The travelling time in the small cell network, $T$, can be predicted using (1) [14].

$T=\frac{R^{2}-r^{2}-d^{2}}{d v}$

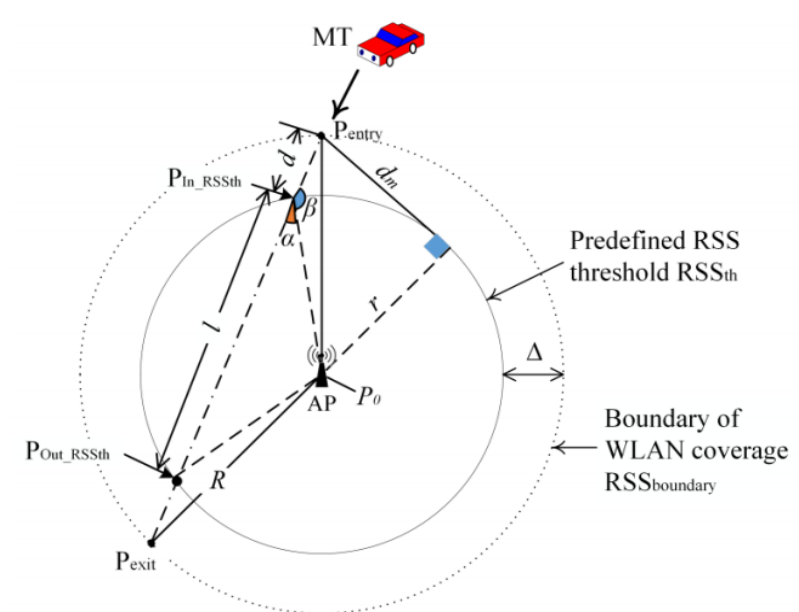

Fig. 1. MT Trajectory within Small Cell Network [14]. 
where $R$ denotes the radius of the access point (AP), $r$ is the radius of AP and Predefined RSS threshold. $d$ represents MT travelling distance between the $P_{\text {in } \_ \text {RSSth }}$ and $P_{\text {entry. }} . v$ is the velocity of the MT, and it can be obtained through the vehicle/ambulance's speedometer. The $R$ and $r$ values can be calculated by using the Log-distance path loss model as described in [14].

\section{B. Fuzzy-Analytic Hierarchy Process}

The first step of the FAHP is to create a decision matrix regarding its parameters for each access network [15] as illustrated as in (2).

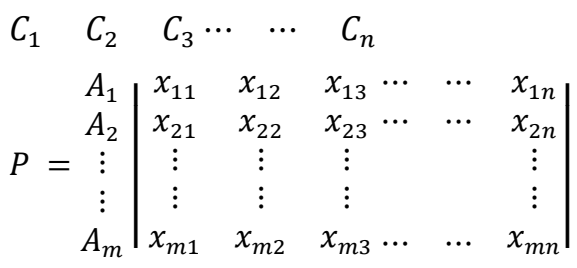

where $A_{i}$ ( $i$ from 1 to $m$ ) represents the network candidate, $C_{j}$ (j from 1 to $n$ ) denotes the criteria used for handover and $x_{i j}$ represents the value of the network $i$ with respect to the criterion $j$.

Secondly, data in the matrix $P$ need to be normalized and construct the normalize data into normalized decision matrix $r$ given as

$r=\left[\begin{array}{ccccc}r_{11} & \cdots & r_{1 j} & \cdots & r_{1 n} \\ \vdots & \vdots & \vdots & \vdots & \vdots \\ r_{i 1} & \cdots & r_{i j} & \cdots & r_{i n} \\ \vdots & \vdots & \vdots & \vdots & \vdots \\ r_{m 1} & \cdots & r_{m j} & \cdots & r_{m n}\end{array}\right]$

$r_{i j}=\frac{x_{i j}}{\sqrt{\sum_{i=1}^{m} x_{i j}^{2}}} i=1,2, \ldots m, j=1,2, \ldots n$

where $r_{i j}$ is a normalized value of element $x_{i j}$.

After obtaining the normalized matrix, the weight value for each handover criteria can be calculated using FAHP. A pairwise comparison matrix can be determined as follows:

$\tilde{A}=\left(\widetilde{a_{l \jmath}}\right)_{n \times n}=$

$\left[\begin{array}{ccc}(1,1,1) & \left(l_{12} m_{12} u_{12}\right) \cdots & \left(l_{1 n} m_{1 n} u_{1 n}\right) \\ \left(l_{21} m_{21} u_{21}\right) & (1,1,1) \ldots & \left(l_{2 n} m_{2 n} u_{2 n}\right) \\ \left(l_{n 1} m_{n 1} u_{n 1}\right) & \left(l_{n 2} m_{n 2} u_{n 2}\right) \ldots & (1,1,1)\end{array}\right]$

where $l, m, u$ denotes the lower bound value, mid-value and upper bound of the triangular fuzzy number based on Satty's AHP scale table as shown in Table I.

\section{TABLE I. SATTY's AHP SCALE}

\begin{tabular}{|l|l|l|}
\hline Linguistic terms & $\begin{array}{l}\text { Fuzzy triangular } \\
\text { numbers }\end{array}$ & $\begin{array}{l}\text { Reciprocal fuzzy } \\
\text { triangular numbers }\end{array}$ \\
\hline Equally important & $(1,1,1)$ & $(1,1,1)$ \\
\hline Moderately important & $(2,3,4)$ & $(1 / 4,1 / 3,1 / 2)$ \\
\hline Strongly important & $(4,5,6)$ & $(1 / 6,1 / 5,1 / 4)$ \\
\hline Very strongly important & $(6,7,8)$ & $(1 / 8,1 / 7,1 / 6)$ \\
\hline Absolutely important & $(7,9,9)$ & $(1 / 9,1 / 9,1 / 7)$ \\
\hline
\end{tabular}

Next is to calculate the Fuzzy geometric mean value $\widetilde{r}_{1}$ given as.

$$
\widetilde{r}_{1}=\left(l_{1} m_{1} u_{1}\right) \otimes\left(l_{2} m_{2} u_{2}\right)^{\frac{1}{n}}
$$

where $n$ represents the number of criteria. After obtaining the Fuzzy geometric mean value, the fuzzy weight $\widetilde{w_{1}}$ can be obtained as follows:

$\widetilde{w_{1}}={\widetilde{r_{1}}}_{1} \otimes\left(\widetilde{r_{1}} \oplus \widetilde{r_{2}} \oplus \ldots \oplus \widetilde{r_{\mathrm{n}}}\right)^{-1}$

Lastly, the defuzzification process is applied to fuzzy weight to obtain the value of the weights $w_{i}$, given as.

$w_{i}=\left(\frac{l+m+u}{3}\right)$

The normalized weights of each criterion can be obtained by.

Normalized Weight $=\frac{\text { Weights }}{\text { Sum of Weights }}$

\section{TOPSIS}

The TOPSIS approach ranks the network candidates and finds the best network based on the user preference and the telemedicine service requirements. After the user rates every criterion based on Table I, weights can be obtained. In the defuzzification process, the normalized decision matrix $\tilde{P}$ will be multiplied with the fuzzy weight array $w_{i}$ to obtain the weighted normalized decision matrix $\tilde{X}$.

$\tilde{X}=\tilde{P} * w_{i}=\left[\begin{array}{ccccc}w_{1} x_{11} & \cdots & w_{j} x_{1 j} & \cdots & w_{n} x_{1 n} \\ \vdots & \vdots & \vdots & \vdots & \vdots \\ w_{1} x_{i 1} & \cdots & w_{j} x_{i j} & \cdots & w_{n} x_{i n} \\ \vdots & \vdots & \vdots & \vdots & \vdots \\ w_{1} x_{m 1} & \cdots & w_{j} x_{m j} & \cdots & w_{n} x_{m n}\end{array}\right]$

Based on the normalized decision matrix $\tilde{X}$, the fuzzy positive ideal solution (FPIS) and fuzzy negative ideal solution (FNIS) can be obtained as follows:

$\tilde{I}^{+}=\left(X_{1}^{+}, \ldots, X_{j}^{+}, \ldots, X_{n}^{+}\right)$

$\tilde{I}^{-}=\left(X_{1}^{-}, \ldots, X_{j}^{-}, \ldots, X_{n}^{-}\right)$

where $X_{j}^{+}$denotes the $\max _{i} X_{i j}$ and $X_{j}^{-}$is the $\min _{i} X_{i j}$.

Then calculate the distances to fuzzy positive and negative ideal solutions, as expressed by (13 and (14), respectively.

$\tilde{d}_{i}^{+}=\sqrt{\sum_{j=1}^{n}\left(\tilde{X}_{i j}-\tilde{I}_{j}^{+}\right)^{2}}$

$\tilde{d}_{i}^{-}=\sqrt{\sum_{j=1}^{n}\left(\tilde{X}_{i j}-\tilde{I}_{j}^{-}\right)^{2}}$

where $\widetilde{d_{l}^{+}}$represents the distance to the FPIS from alternative $i$ and $\widetilde{d_{l}^{-}}$is the distance to the FNIS from alternative $i$.

Finally, the computation of the fuzzy relative closeness for each alternative is applied. Let $\widetilde{C}_{l}$ represents the fuzzy relative closeness coefficient for alternative $i$. It denotes the degree of proximity to the positive ideal solution. If the computed $\widetilde{C}_{l}$ is nearly 1 , it infers that alternative $i$ approaches the positive ideal solution. It might be the best one among other alternatives. On 
the other hand, if $\widetilde{C}_{l}$ is far less than 1 , alternative $i$ will not be the best one. Fuzzy relative closeness coefficient can be obtained by.

$\widetilde{C_{l}}=\frac{\widetilde{d_{l}}}{\widetilde{d_{l}}+\widetilde{d_{l}^{+}}}(i=1,2, \ldots, n)$

The $\widetilde{C}_{l}$ values are averaged and are ranked all network candidates in descending order. The highest value of $\widetilde{C}_{l}$ will be the most appropriate network to handover. The flowchart of the proposed handover algorithm is shown in Fig. 2.

The proposed handover algorithm starts with monitoring the quality-of-service (QoS) of the serving network, user preference and services requirements such as video, voice, electrocardiogram (ECG) and vital signs. If the QoS of the serving network meets the services requirements and user preference, MT will stay connected to the serving network and continue monitoring the network QoS. Otherwise, the proposed algorithm will scan for alternate networks to search for a better network to maintain the quality of services. The proposed algorithm will first check if any small cell network is detected. If any small cell network is detected, the travelling time estimation algorithm will be used to predict the travelling time within the network. Only the network candidates whose estimated travelling time are greater than the threshold value will proceed to the next step, FAHP and TOPSIS algorithms, for network quality evaluation. Otherwise, the algorithm will reject it and scan for alternate networks. If a large cell network such as an LTE network is detected, the proposed algorithm will directly proceed to the FAHP and TOPSIS algorithm because large cell networks could support the MT moving at high speed.

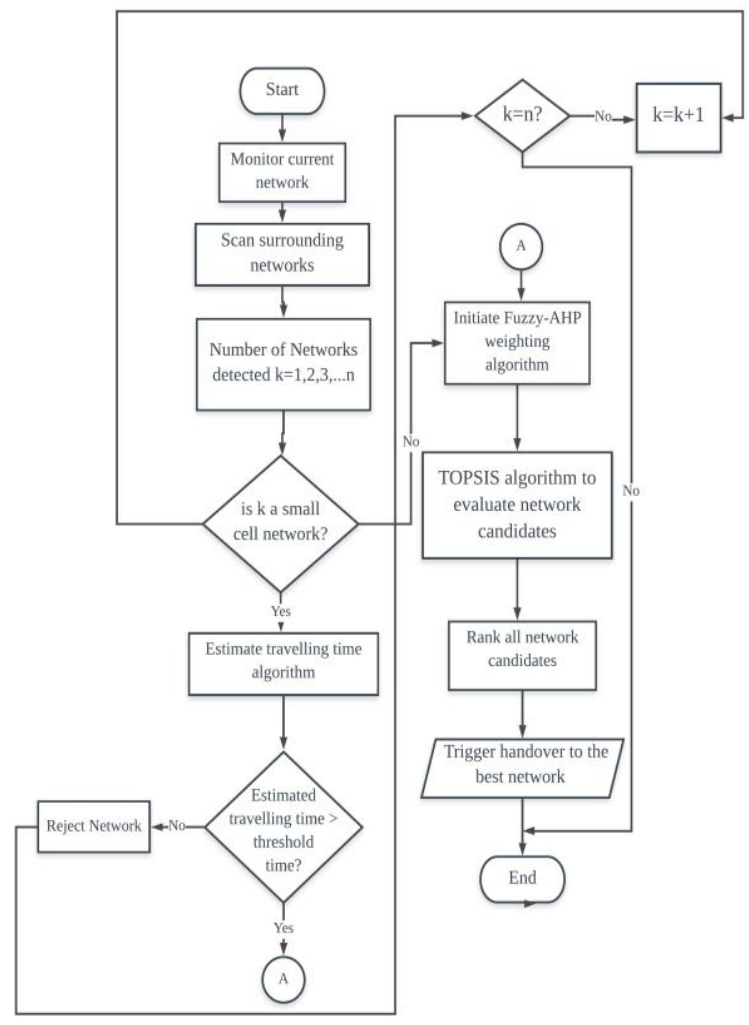

Fig. 2. Proposed Vertical Handover Algorithm.
The FAHP algorithm calculates the weight for each handover criterion used in TOPSIS based on the user preference rating. For example, users can choose and rate the criteria using the linguistic term for the low-cost network such as WLAN. After obtaining the weights, the TOPSIS algorithm will evaluate all the network candidates and form a ranking system to determine which network is the best. The best network candidate will be chosen for handover.

\section{EXPERIMENT SETUP}

A 5G heterogeneous wireless networks environment that consists of WLAN, LTE, and 5G, as shown in Fig. 3, is created using MATLAB to evaluate the performance of the proposed handover scheme. The network coverage diameter for WLAN, $5 \mathrm{G}$ and LTE is $120 \mathrm{~m}, 300 \mathrm{~m}$, and $16 \mathrm{~km}$, respectively. The LTE network covers all 5G and WLAN cells. The handover parameters considered in this work are cost, delay, data rate, and packet loss rate (PLR), as tabulated in Table III.

Assuming that the MT (ambulance) moves from point A to destination $\mathrm{B}$. It traverses the $5 \mathrm{G}$ heterogeneous networks at high speed and transmitting real-time ECG, audio, vital, and voice to the healthcare centre. The total bandwidth required for the telemedicine service is 829 Kbps [20], as shown in Table II. The ambulance was initially connected to the LTE network. It traverses the network 5G1, followed by WLAN 1, $5 \mathrm{G} 2$, WLAN 2, 5G 3, 5G 4, WLAN 3 and WLAN 4.The proposed handover algorithm selects the most suitable network based on service requirements and user preference.

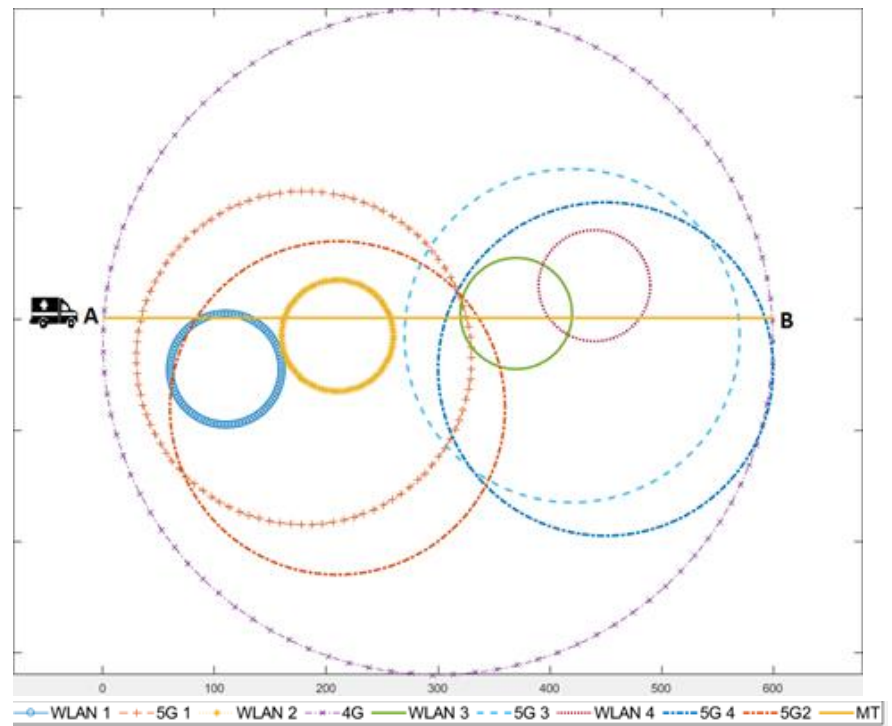

Fig. 3. Heterogeneous Wireless Networks Environment.

TABLE II. BANDWIDTH REQUIREMENT FOR TELEMEDICINE [20]

\begin{tabular}{|l|l|}
\hline Services & Bandwidth \\
\hline Video & $640-5000 \mathrm{kbps}$ \\
\hline Audio & $32-256 \mathrm{kbps}$ \\
\hline ECG & $24 \mathrm{kbps} / 12 \mathrm{leads}$ \\
\hline Vital Signs & $2-5 \mathrm{kbps}$ \\
\hline
\end{tabular}


TABLE III. SimUlation PARAMETERs [16, 20, 21].

\begin{tabular}{|l|l|l|l|}
\hline Parameters & LTE & $5 \mathrm{G}$ & WLAN \\
\hline Carrier frequency & $1.9 \mathrm{GHz}$ & $26 \mathrm{GHz}$ & $2.4 \mathrm{GHz}$ \\
\hline Coverage (radius) & $16 \mathrm{~km}$ & $300 \mathrm{~m}$ & $120 \mathrm{~m}$ \\
\hline Data rate & $20 \mathrm{Mbps}$ & $1 \mathrm{Gbps}$ & $50 \mathrm{Mbps}$ \\
\hline Cost & 8 & 60 & 1 \\
\hline Delay (ms) & 15 & 1 & 7 \\
\hline PLR & 0.001 & 0.0001 & 0.002 \\
\hline
\end{tabular}

\section{RESUlt AND Discussion}

In order to obtain weights based on user preference, the value of the pair-wise comparison matrix is set by the user based on Satty's AHP scale shown in Table IV. Assuming the user wants to save cost and set the cost parameter extremely preferred over all other criteria. While comparing with the same criteria, it will be equally important and cannot be changed by the user.

With the data collected from Table IV, the mean and sum of Fuzzy Geometric values can be obtained using (6), and the results are tabulated in Table $\mathrm{V}$. These values are used for calculating the fuzzy weight. The fuzzy weight can be concluded into three values that are $l, m, u$ to form a fuzzy triangular number which stands for lower bound value, midvalue and upper bound, respectively, as shown in Table VI. The next step is the defuzzification process to get the normalized weight value for each criterion. Defuzzification is defined as changing the fuzzy weight number into a single crisp weight value by applying (8). Normalized weights for each criterion are shown in Table VII. The cost has the highest weightage compared to other parameters. As a result, the handover algorithm is biased to low cost networks such as WLAN because it has the lowest cost compared to LTE and $5 \mathrm{G}$.

The handover performed by the proposed handover algorithm with MT moving at $60 \mathrm{~km} / \mathrm{h}$ is illustrated in Fig. 4, while Fig. 5 shows the handover performance of FAHPTOPSIS based handover algorithm [15]. It can be seen in Fig. 4, the proposed handover algorithm did not handover to WLAN 1 because the travelling time of WLAN 1 is less than 2 seconds, while the FAHP-TOPSIS based handover algorithm handovers to any WLANs detected by MT (as shown in Fig. 5). Additionally, the algorithm handovers to LTE instead of 5G is because the $5 \mathrm{G}$ cost is higher than LTE. Therefore, the proposed algorithm handover to LTE right after disconnecting from WLAN.

The performance of the proposed handover algorithm at the speed of $120 \mathrm{~km} / \mathrm{h}$ can be seen in Fig. 6. It did not handover to WLAN 1 and WLAN 2 because the travelling time within the WLAN 1 and WLAN 2 was less than 2 seconds when the MT travelled at the speed of $120 \mathrm{~km} / \mathrm{h}$. The travelling time becomes shorter due to MT traverses the network at a higher speed. The proposed algorithm only handovers to WLAN 5 and WLAN 7. However, the FAHP-TOPSIS based handover algorithm handovers to WLAN whenever it is available and ping pong effect is higher than the proposed algorithm, as shown in Fig. 7. The total number of handovers and unnecessary handovers of the proposed handover algorithm is significantly reduced compared with FAHP-TOPSIS based handover algorithm, as shown in Table VIII.

TABLE IV. MEAN AND SUm of FuZZy GeOMEtric Value

\begin{tabular}{|c|c|c|c|}
\hline & \multicolumn{3}{|c|}{ FUZZY GEOMETRIC MEAN VALUE $\left(\widetilde{r_{1}}\right)$} \\
\hline & 5.061 & 6.240 & 6.240 \\
\hline & 0.693 & 0.693 & 1.504 \\
\hline & 0.577 & 0.693 & 1.252 \\
\hline & 0.480 & 0.693 & 1.043 \\
\hline & 0.399 & 0.693 & 0.868 \\
\hline & 0.333 & 0.693 & 0.723 \\
\hline Sum of geometric value & 7.543 & 9.705 & 11.630 \\
\hline $\mathbf{r}^{-1}$ & 0.086 & 0.103 & 0.133 \\
\hline
\end{tabular}

TABLE V. PAIR-Wise COMPARISON MATRIX FOR CRITERIA WEIGHTS

\begin{tabular}{|c|c|c|c|c|c|c|c|c|c|c|c|c|c|c|c|c|c|c|}
\hline \multirow[b]{2}{*}{ Cost } & \multicolumn{3}{|c|}{ COST } & \multicolumn{3}{|l|}{ DR } & \multicolumn{3}{|c|}{ DELAY } & \multicolumn{3}{|c|}{ PLR } & \multicolumn{3}{|c|}{ BER } & \multicolumn{3}{|c|}{ SINR } \\
\hline & 1 & 1 & 1 & 7 & 9 & 9 & 7 & 9 & 9 & 7 & 9 & 9 & 7 & 9 & 9 & 7 & 9 & 9 \\
\hline DR & $1 / 9$ & $1 / 9$ & $1 / 7$ & 1 & 1 & 1 & 1 & 1 & 3 & 1 & 1 & 3 & 1 & 1 & 3 & 1 & 1 & 3 \\
\hline DELAY & $1 / 9$ & $1 / 9$ & $1 / 7$ & $1 / 3$ & 1 & 1 & 1 & 1 & 1 & 1 & 1 & 3 & 1 & 1 & 3 & 1 & 1 & 3 \\
\hline PLR & $1 / 9$ & $1 / 9$ & $1 / 7$ & $1 / 3$ & 1 & 1 & $1 / 3$ & 1 & 1 & 1 & 1 & 1 & 1 & 1 & 3 & 1 & 1 & 3 \\
\hline BER & $1 / 9$ & $1 / 9$ & $1 / 7$ & $1 / 3$ & 1 & 1 & $1 / 3$ & 1 & 1 & $1 / 3$ & 1 & 1 & 1 & 1 & 1 & 1 & 1 & 3 \\
\hline SINR & $1 / 9$ & $1 / 9$ & $1 / 7$ & $1 / 3$ & 1 & 1 & $1 / 3$ & 1 & 1 & $1 / 3$ & 1 & 1 & $1 / 3$ & 1 & 1 & 1 & 1 & 1 \\
\hline
\end{tabular}

TABLE VI. FuZZY Weight VALUES

\begin{tabular}{|l|l|l|l|}
\cline { 2 - 4 } \multicolumn{1}{c|}{} & Fuzzy Weight, $\boldsymbol{W}_{\boldsymbol{i}}$ & Mid-Value & Upper Bound \\
\hline COST & Lower Bound & 0.643 & 0.83 \\
\hline DR & 0.435 & 0.071 & 0.2 \\
\hline DELAY & 0.060 & 0.071 & 0.167 \\
\hline PLR & 0.050 & 0.071 & 0.139 \\
\hline BER & 0.041 & 0.071 & 0.115 \\
\hline SINR & 0.034 & 0.071 & 0.096 \\
\hline
\end{tabular}


TABLE VII. WEIGHT OF EACH CRITERION

\begin{tabular}{|l|l|l|}
\cline { 2 - 3 } \multicolumn{1}{c|}{} & Weights & Normalized Weight \\
\hline COST & 0.636 & 0.598 \\
\hline DR & 0.11 & 0.103 \\
\hline DELAY & 0.096 & 0.09 \\
\hline PLR & 0.084 & 0.079 \\
\hline BER & 0.073 & 0.069 \\
\hline SINR & 0.065 & 0.061 \\
\hline TOTAL & $\mathbf{1 . 0 6 4}$ & $\mathbf{1}$ \\
\hline
\end{tabular}

TABLE VIII. PERFormanCE OF THE PROPOSED HANDOVER AlgORITHM AND FAHP-TOPSIS BASED HANDOVER ALGORITHM FOR SINGLE ITERATION

\begin{tabular}{|l|l|l|l|l|}
\hline \multirow{2}{*}{$\begin{array}{l}\text { MT } \\
\text { velocity }\end{array}$} & \multicolumn{2}{|l|}{ Total Handover } & \multicolumn{2}{l|}{ Unnecessary Handover } \\
\cline { 2 - 5 } & FAHP-TOPSIS & Proposed & FAHP-TOPSIS & Proposed \\
\hline $60 \mathrm{~km} / \mathrm{h}$ & 20 & 5 & 15 & 0 \\
\hline $120 \mathrm{~km} / \mathrm{h}$ & 21 & 3 & 18 & 0 \\
\hline
\end{tabular}

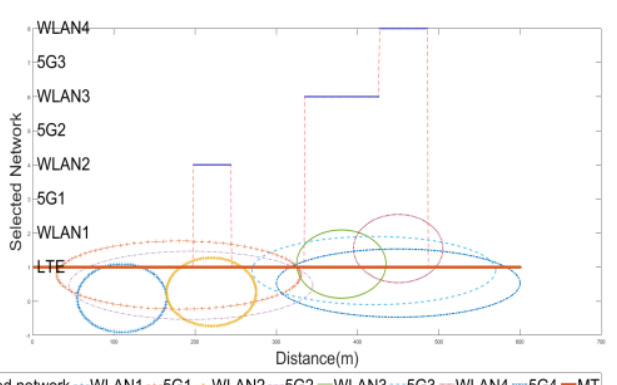

selected network -WLAN1 -5 G1 WLAN2 5 5G2 - WLAN3 - 5G3 - WLAN4 -5G4-MT

Fig. 4. Handover Performed by the Proposed Handover Algorithm at the Speed of $60 \mathrm{~km} / \mathrm{h}$.

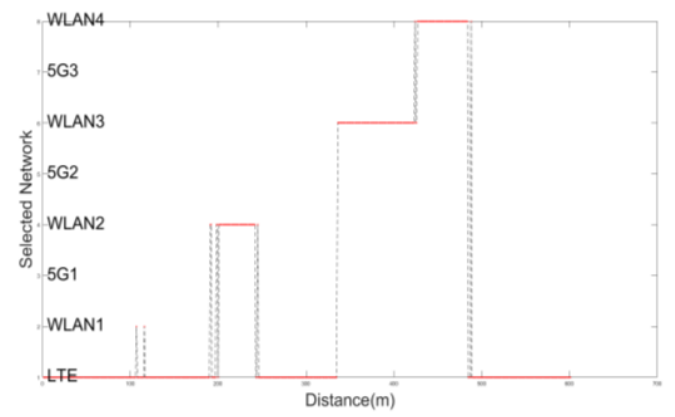

Fig. 5. Handover Performed by FAHP-TOPSIS based Handover Algorithm at the Speed of $60 \mathrm{~km} / \mathrm{h}$.

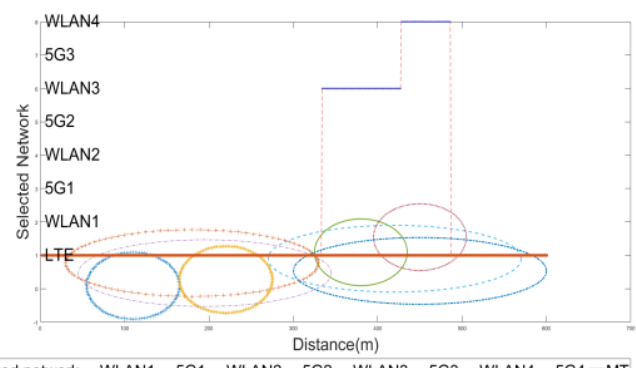

- selected network - WLAN1 $-5 \mathrm{G} 1$-WLAN2 $-5 \mathrm{G} 2-$ WLAN3 $\cdots 5 \mathrm{G} 3-$ WLAN4 $-5 \mathrm{G} 4-$ MT

Fig. 6. Handover Performed by the Proposed Handover Algorithm at the Speed of $120 \mathrm{~km} / \mathrm{h}$.

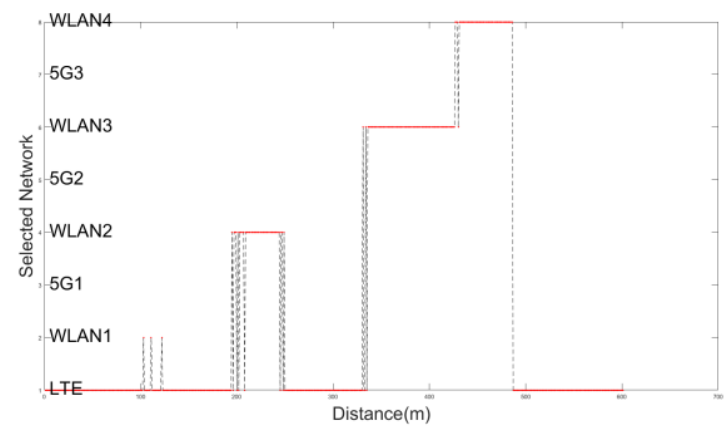

Fig. 7. Handover Performed by FAHP-TOPSIS based Handover Algorithm at the Speed of $120 \mathrm{~km} / \mathrm{h}$.

The proposed handover algorithm has been simulated for 500 iterations to obtain more accurate results. The total number of handovers performed by the proposed handover algorithm and FAHP-TOPSIS based handover algorithm is 2514 and 12776, respectively. The proposed algorithm has reduced the number of handovers up to $80.3 \%$ compared to FAHP-TOPSIS based handover algorithm [15]. The FAHP-TOPSIS based handover algorithm [15] induces a high number of unnecessary handovers when the MT travels at high speed. With the implementation of the prediction technique, the proposed handover algorithm has significantly reduced the number of unnecessary handovers in the high-speed scenario. Additionally, the ping-pong effect is also greatly reduced in the proposed handover algorithm.

\section{CONCLUSION}

This paper proposed a new handover algorithm that integrates travelling time estimation, FAHP and TOPSIS algorithms. The proposed handover algorithm has improved the handover performance in the high-speed scenario. The number of unnecessary handovers has been greatly reduced. Additionally, the strength of the proposed handover algorithm is that it uses the fuzzy set theory to eliminate uncertainty and vagueness throughout the pairwise comparison process and travelling time prediction algorithm to minimize unnecessary handover to small cell networks. Furthermore, the TOPSIS approach ranks and finds the best network candidate based on user preference and telemedicine service requirements. The proposed handover algorithm has significantly minimized the number of unnecessary handovers and improved user satisfaction by selecting the lower cost network while maintaining the quality of telemedicine service.

In this work, we assumed the speed of MT is constant while traversing the network. It may cause an increase in the probability of unnecessary handover if MT is accelerating because MT will leave the network coverage earlier than the estimated time. The performance of the proposed handover decision making algorithm can be further improved if the algorithm adapts to change in MT velocity.

\section{REFERENCES}

[1] H. T. Yew, C. S. Kheau, R. K. Y. Chin, A. Chekima, and M. H. Satria, "Improved-TOPSIS based handover scheme for telemedicine service using heterogeneous wireless networks," Proc. - 2017 IEEE 2nd Int. Conf. Autom. Control Intell. Syst. I2CACIS 2017, vol. 2017-Decem, no. October, pp. 155-160, 2017. 
[2] C. S. Kruse, M. Soma, D. Pulluri, N. T. Nemali, and M. Brooks, "The effectiveness of telemedicine in the management of chronic heart disease - a systematic review," JRSM Open, vol. 8, no. 3, p. $205427041668174,2017$.

[3] H. Kim, “ 5G Wireless Communication System Parameters and Requirements ," Des. Optim. 5G Wirel. Commun., pp. 13-20, 2020.

[4] S. Mukhopadhyay, V. Agarwal, S. Sharma, and V. Gupta, "A Study On Wireless Communication Networks Based On Different Generations," Int. J. Curr. Trends Eng. Res., vol. 2, no. 5, pp. 300-304, 2016.

[5] I. Chattate, J. Bakkoury, A. Khiat, and M. El Khaili, "Overview on technology of vertical handover and MIH architecture,” Colloq. Inf. Sci. Technol. Cist, vol. 0, pp. 31-34, 2016.

[6] E. Popovici, O. Fratu, A. Vulpe, and S. Halunga, "New developments in vertical handover based on media independent handover standard," Wirel. Pers. Commun., vol. 78, no. 3, pp. 1739-1753, 2014.

[7] H. T. Yew, A. Chekima, A. Kiring, A. I. Mbulwa, J. A. Dargham, and S. K. Chung, "RSS Based Vertical Handover Schemes in Heterogeneous Wireless Networks: Past, Present Future,” IEEE Int. Conf. Artif. Intell. Eng. Technol. IICAIET 2020, no. September, 2020.

[8] A. Mahmood, H. Zen, A. K. Othman, and S. A. Siddiqui, "A novel travelling time estimation mechanism for minimizing unnecessary handovers from cellular networks to WLANs," Proc. 2nd Int. Conf. Inf. Technol. Electron. Commer. ICITEC 2014, pp. 38-42, 2014.

[9] S. K. Chung, M. I. Goh, H. T. Yew, B. L. Chua, S. S. Husain, and A. I Mbulwa, "Enhanced Bandwidth Based Handover Decision Making Algorithm for Small Cell Wireless Networks," IEEE Int. Conf. Artif. Intell. Eng. Technol. IICAIET 2020, no. September, 2020.

[10] H. T. Yew, E. Supriyanto, M. H. Satria, and Y. W. Hau, "Adaptive network selection mechanism for telecardiology system in developing countries," in 3rd IEEE EMBS International Conference on Biomedical and Health Informatics, BHI 2016, 2016.

[11] H. T. Yew, E. Supriyanto, M. Haikal Satria, and Y. W. Hau, "Usercentric based vertical handover decision algorithm for telecardiology application in heterogeneous networks," J. Teknol., vol. 77, no. 7, pp 79-83, 2015.

[12] S. Bhat, A. Mukhopadhyay, and B. K. Sandhya Rani, "Dynamic media selection between WiFi and LTE in telemedicine scenarios," 2017 Int. Conf. Adv. Comput. Commun. Informatics, ICACCI 2017, vol. $2017-$ Janua, pp. 601-606, 2017.

[13] A. Mukhopadhyay, R. R. Hegde, and A. S. Thomas, "Handover mechanisms in wireless heterogeneous telemedicine networks," Proc. 3rd Int. Conf. Comput. Methodol. Commun. ICCMC 2019, no. Iccmc, pp. 938-945, 2019.

[14] Hoe-tung Yew, E. Supriyanto, M. H. Satria, and Y. Hau, “A Vertical Handover Management for Mobile Telemedicine System using Heterogeneous Wireless Networks," Int. J. Adv. Comput. Sci. Appl., vol. 7, no. 7, pp. 1-9, 2016.

[15] V. Sasirekha and M. Ilanzkumaran, "Heterogeneous wireless network selection using FAHP integrated with TOPSIS and VIKOR,” Proc. 2013 Int. Conf. Pattern Recognition, Informatics Mob. Eng. PRIME 2013, pp. 399-407, 2013.

[16] X. Tan, G. Chen, and H. Sun, "Vertical handover algorithm based on multi-attribute and neural network in heterogeneous integrated network," Eurasip J. Wirel. Commun. Netw., vol. 2020, no. 1, pp. 1-21, 2020.

[17] A. F. Almutairi, M. Hamed, M. A. Landolsi, and M. Algharabally, "A genetic algorithm approach for multi-attribute vertical handover decision making in wireless networks," Telecommun. Syst., vol. 68, no. 2, pp. $151-161,2018$.

[18] H. W. Yu and B. Zhang, "A heterogeneous network selection algorithm based on network attribute and user preference," Ad Hoc Networks, vol. 72, pp. 68-80, 2018.

[19] H. T. Yew, E. Supriyanto, M. H. Satria, and Y. W. Hau, "New vertical handover method to optimize utilization of wireless local area network in high-speed environment," PLoS One, vol. 11, no. 11, 2016.

[20] H. T. Yew, Y. Aditya, H. Satrial, E. Supriyanto, and Y. W. Hau, "Telecardiology System for Fourth Generation," vol. 10, no. 2, pp. 600$607,2015$.

[21] E. O’Connell, D. Moore, and T. Newe, "Challenges Associated with Implementing 5G in Manufacturing," Telecom, vol. 1, no. 1, pp. 48-67, 2020 . 